\title{
Nifedipine Suppresses Self-Injurious Behaviors in Animals
}

\author{
Bonita L. Blake ${ }^{a}$ Amber M. Muehlmann ${ }^{b}$ Kiyoshi Egamic George R. Breese ${ }^{a}$ \\ Darragh P. Devine ${ }^{b}$ H.A. Jinnah ${ }^{c}$ \\ ${ }^{a}$ Departments of Psychiatry and Pharmacology, University of North Carolina, Chapel Hill, N.C., b Department of

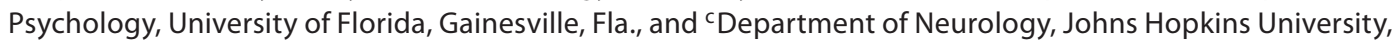 \\ Baltimore, Md., USA
}

\section{Key Words}

Nifedipine $\cdot$ Behavior, self-injurious · Therapy

\begin{abstract}
Self-injurious behavior is a common problem in many developmental disorders. The neurobiology of this behavior is not well understood, but the differing behavioral manifestations and associations with different disorders suggest that the underlying biological mechanisms are heterogeneous. The behavioral and biological heterogeneity is also evident in several animal models, where different manifestations can be provoked under different experimental conditions. Identifying commonalities among the different mechanisms is likely to be helpful in the design of treatments useful for the broadest populations of patients. The current studies reveal that nifedipine suppresses self-injurious behavior in 4 unrelated animal models: acute administration of high doses of \pm BayK 8644 or methamphetamine in mice, dopamine agonist treatment in rats with lesions of dopamine pathways during early development and repeated administration of pemoline in rats. The effect of nifedipine does not appear to be due to nonspecific mechanisms, such as sedation, since other classes of behaviors are unaffected or exaggerated. These results suggest that nifedipine may target a common biological mechanism in the expression of self-injurious behavior, and they suggest it should be considered in the treatment of self-injury in humans. Copyright $\odot 2006 \mathrm{~S}$. Karger AG, Basel
\end{abstract}

\section{Introduction}

Self-injurious behavior (SIB) in humans is characterized by acts such as head banging, eye poking, biting the digits or limbs, self-hitting, hair pulling, skin picking and others [Schroeder et al., 2001]. These behaviors occur in a number of different developmental disorders. They are most common in mental retardation and autism, but they also occur in specific neurogenetic syndromes such as Lesch-Nyhan disease [Anderson and Ernst, 1994; Robey et al., 2003] and Prader-Willi syndrome [Symons et al., 1999].

The biological basis of SIB is not well understood, and the treatment is challenging. The many different manifestations and the associations with many different disorders suggest that the underlying neurobiological mechanisms are heterogeneous. In this setting the design of rational therapies useful in the broadest populations of patients may benefit from identifying shared biological mechanisms.

Several animal models have been developed to study the biology of SIB. It has long been known that SIB emerges in a variety of species treated with high doses or chronic administration of psychostimulants, including amphetamine [Huberman et al., 1977; Mueller et al., 1982; Sokol et al., 1991; Kratofil et al., 1996], methamphetamine [Kita et al., 2000; Kasim and Jinnah, 2002; Halladay et al., 2003] and pemoline [Mueller and Nyhan, 1982; Mueller

H.A. Jinnah, $\mathrm{MD}, \mathrm{PhD}$

Meyer Room 6-181

600 North Wolfe Street

Baltimore, MD 21287 (USA)

Tel. +1 410614 6551, Fax +1 410502 6737, E-Mail hjinnah@jhmi.edu 
et al., 1986; King et al., 1995, 1998; Cromwell et al., 1999; Kies and Devine, 2004]. These behaviors are often preceded or accompanied by hyperactive locomotor behavior and multiple stereotypical behaviors such as grooming and licking. The mechanisms responsible for SIB in the psychostimulant models remain incompletely understood but are likely to involve their ability to stimulate the release of monoamines in the brain. In fact SIB also results from direct microinjection of amphetamine into the striatum of rats, suggesting a release of dopamine in this region to play a key role [Kelley et al., 1988, 1989; Dickson et al., 1994].

SIB may also occur after chronic delivery of very high doses of caffeine and theophylline in mice and rats [Mueller et al., 1982; Kies and Devine, 2004]. The mechanism responsible for SIB in this model is poorly understood but thought to involve disruption of dopaminergic or adenosinergic systems in the striatum [Jinnah et al., 1990]. Another well-studied animal model for SIB involves making lesions of brain dopaminergic pathways with the toxin 6-hydroxydopamine (6OHDA) during early postnatal development in rats, followed by pharmacological challenge with dopamine agonists after $1 \mathrm{month}$ of age [Breese et al., 2004]. Rats treated in this way develop hyperactivity, multiple stereotypical behaviors and SIB. Extensive studies of this model have led to the conclusion that SIB results from overstimulation of striatal dopamine receptors that have been sensitized by dopamine depletion and subsequent agonist challenges.

More recently SIB has been shown to occur in mice and rats after administration of \pm BayK 8644 , an activator of voltage-regulated (L-type) calcium channels [Jinnah et al., 1999; Kasim et al., 2002; Kasim and Jinnah, 2003]. Unlike the psychostimulant or 6OHDA models, SIB in this model emerges within minutes after the first dose and is accompanied by dystonic motor behavior rather than stereotypical behaviors. Further studies of this model have indicated that striatal dopamine receptors play a role in the expression of SIB in this model and that SIB can be markedly attenuated by nifedipine, an Ltype calcium channel antagonist [Jinnah et al., 1999; Kasim and Jinnah, 2003; Kasim et al., 2006].

SIB is a complex behavior that is likely to involve abnormal function or interaction among multiple cortical and subcortical brain regions. The observation that many animal models for SIB share the common feature of dysfunction of striatal dopamine pathways suggests that these pathways are involved in the neural systems generating SIB. Dysfunction of these pathways is also thought to underlie SIB in several human conditions [Visser et al.,
2000]. At the biochemical level, the observation that striatal dopamine receptors are coupled to L-type calcium channels suggests the possibility that these channels might serve as a common mechanistic link for the expression of SIB. If this is the case, blockers of these channels might suppress SIB in many different animal models. We therefore tested the ability of nifedipine to suppress SIB in 4 different animal models.

\section{Methods}

Experimental Strategy

The goal of these experiments was to assess the efficacy of nifedipine for suppressing SIB across 4 different animal models, each involving very different methods. The models included subcutaneous administration of \pm BayK 8644 or methamphetamine mice, repeated daily administration of pemoline in rats and dopamine agonist challenge in rats with prior 6OHDA lesions. The caffeine model of SIB was not evaluated because of concerns related to its profound behavioral toxicity [Kasim and Jinnah, 2002; Kies and Devine, 2004]. Each model was tested independently by an experienced research group, according to methods previously established for producing the most robust and reliable expression of SIB in the model.

No attempt was made to force the models to conform to specific standardized conditions including animal species, age or sex. As a result rigorous quantitative comparisons among the groups were not feasible. The main focus of these studies was on SIB; changes in ancillary behaviors were collected and presented only where they were useful to demonstrate specificity of behavioral effects.

\section{Animals}

All animals were housed with free access to food and water, and all experimental procedures were conducted in accordance with the Guide for the Care and Use of Laboratory Animals and were approved by the Animal Care and Use Committee of the appropriate institution. In order to prevent unnecessary pain and suffering, significant SIB was terminated whenever it occurred by the administration of $20 \mathrm{mg} / \mathrm{kg}$ of nifedipine or a sedative.

The \pm BayK 8644 model has been characterized in young C57BL/6J mice, where SIB occurs without bias according to sex. This model therefore included 4-week-old male and female mice of this mouse strain. The expression of SIB in the methamphetamine model depends on mouse strain, sex and housing conditions. The conditions selected to optimize expression of SIB for this model involved the use of the $\mathrm{Balb} / \mathrm{c}$ mouse strain, male sex and isolation housing for 1 week. The 6OHDA and pemoline models have both been best characterized in rats, with little or no data available for mice. These models were therefore tested using rats rather than mice. The strain of rat was chosen according to the preferences of the test site.

\section{\pm BayK 8644 Model}

Normal C57BL/6J mice were obtained from the Jackson Laboratories (Bar Harbor, Me., USA) and bred and maintained at Johns Hopkins University in groups of 2-12 with free access to food and 
water at all times. \pm BayK 8644 was obtained from Sigma-RBI (St. Louis, Mo., USA), and a stock solution of $10 \mathrm{mg} / \mathrm{ml}$ was prepared by dissolving in a mixture containing equal parts of ethanol and Tween-80. The stock was stored in amber vials at $4^{\circ} \mathrm{C}$ for up to 1 month and freshly diluted with distilled water immediately before it was used at a total volume of $10 \mathrm{ml} / \mathrm{kg}$.

Independent groups of drug-naïve $\mathrm{C} 57 \mathrm{BL} / 6 \mathrm{~J}$ mice each received 2 , 4 , or $8 \mathrm{mg} / \mathrm{kg}$ of \pm BayK 8644 . Five minutes prior to the \pm BayK 8644 injections, half of each \pm BayK 8644 dose group received a subcutaneous injection of $20 \mathrm{mg} / \mathrm{kg}$ of 1 of 5 calcium channel antagonists, while the other half received subcutaneous injections of vehicle as controls. The behaviors were assessed as previously described [Kasim et al., 2002, 2006; Kasim and Jinnah, 2003]. The animals were observed for $1 \mathrm{~min}$ every $10 \mathrm{~min}$ for $1 \mathrm{~h}$ immediately following \pm BayK 8644 administration, and their behaviors were recorded. Self-biting (SB) was defined as biting any portion of the body without tissue injury, while SIB was defined as biting that resulted in tissue injury. The frequencies of these behaviors were analyzed using the $\chi^{2}$ statistic for nonparametric measures.

\section{Methamphetamine Model}

$\mathrm{Balb} / \mathrm{c}$ mice were obtained from the Jackson Laboratories at 5-6 weeks of age and housed singly at Johns Hopkins University for 1 week prior to behavior testing. SB and SIB in response to methamphetamine depends on strain, sex and housing conditions [Kasim and Jinnah, 2002; Halladay et al., 2003]. To maximize the expression of these behaviors, only male Balb/c mice were evaluated after 1 week of isolation housing.

Methamphetamine was obtained from Sigma-RBI, dissolved in saline and injected subcutaneously at a dose of $10 \mathrm{mg} / \mathrm{kg}$. In the first experiment half of the mice were simultaneously treated with $5 \mathrm{mg} / \mathrm{kg}$ of nifedipine. This experiment was repeated in a second experiment with a fresh group of mice, half of which received $10 \mathrm{mg} / \mathrm{kg}$ of nifedipine. In a third experiment half the mice received $20 \mathrm{mg} / \mathrm{kg}$ of nifedipine.

SB, SIB and other stereotypical behaviors (sniffing, licking and grooming) were evaluated as previously described [Kasim and Jinnah, 2002; Halladay et al., 2003]. Immediately after injection each mouse was observed for 1 min every 15 min for $90 \mathrm{~min}$. The frequencies of SB and SIB were recorded, and the average percentage of time the animals engaged in each stereotypical behavior was estimated by averaging the 6 recording intervals and analyzed using ANOVA.

\section{OHDA Model}

Pregnant Sprague-Dawley rats were obtained from Harlan (Indianapolis, Ind., USA) and housed at the University of North Carolina. Male and female neonates were pretreated with $20 \mathrm{mg} /$ $\mathrm{kg}$ of desipramine subcutaneously at 3-5 days of age to block the uptake of 6OHDA into noradrenergic neurons. Approximately $60 \mathrm{~min}$ later, they were anesthetized with ether and given intracisternal injections of $100 \mu \mathrm{g}$ of 6OHDA (free base) freshly dissolved in $10 \mu \mathrm{l}$ of saline with $0.01 \%$ ascorbic acid. This treatment results in $>95 \%$ loss of dopamine and its axons in the striatum [Papadeas et al., 2004].

The behavioral observations began at 40 days of age. Apomorphine and nifedipine (Sigma-RBI) were prepared fresh on each day. To assess the sensitivity to apomorphine-mediated SB, rats lesioned as neonates were injected with vehicle (dimethylsulfox- ide for nifedipine) intraperitoneally. Ten minutes later they were given a subcutaneous injection of apomorphine at $10 \mathrm{mg} / \mathrm{kg}$ in saline. One week later the same animals were administered 5, 10 or $20 \mathrm{mg} / \mathrm{kg}$ of nifedipine $10 \mathrm{~min}$ prior to $10 \mathrm{mg} / \mathrm{kg}$ of apomorphine. The rats were observed for $1 \mathrm{~min}$ every $10 \mathrm{~min}$ for $90 \mathrm{~min}$, and the frequencies of SB and SIB were analyzed as described above. The percentage of time the rats engaged in various stereotypical behaviors was also estimated at each interval.

\section{Pemoline Model}

Male Long-Evans rats (Charles River Laboratories, Raleigh, N.C., USA) were pair-housed in standard polycarbonate cages (43 $\times 21.5 \times 25.5 \mathrm{~cm}$ ) during $5-7$ days of acclimation to the housing facility. They were tested at 2 months of age. They were singly housed in standard polycarbonate cages during the experimental procedures.

Pemoline (Spectrum Chemicals, New Brunswick, N.J., USA), and nifedipine (Sigma-RBI) suspensions were prepared fresh on each day. The pemoline was suspended at a concentration of $50 \mathrm{mg} / \mathrm{ml}$ in warm peanut oil (held at $37^{\circ} \mathrm{C}$ ) with constant stirring. The rats were injected subcutaneously with $200 \mathrm{mg} / \mathrm{kg}$ of pemoline at approximately 8.00 a.m. on each of 5 consecutive days. Nifedipine was suspended at concentrations of $0,1.5,5$ and $15 \mathrm{mg} / \mathrm{ml}$ in a solution consisting of $40 \%$ propylene glycol, $10 \%$ ethanol, $15 \%$ benzyl alcohol and $35 \%$ distilled water. The rats were injected twice daily with nifedipine $(0,3,10$ or $30 \mathrm{mg} / \mathrm{kg}$ s.c.) on each of the 5 days ( $n=5-6$ per group). The nifedipine injections were administered immediately after the pemoline injections and at approximately 6.00 p.m.

In this model SB and SIB evolve more slowly than in the other models. As a result a different method for behavioral assessment was required [Kies and Devine, 2004]. SIB was evaluated by estimating the time the animals engaged in self-injurious oral contact and by scoring the severity of tissue injury. Self-injurious oral contact was defined as contact between the mouth and any body part, where contact stayed fixed on that body part for longer than $2 \mathrm{~s}$, to differentiate it from grooming. It was recorded in 5-min time samples every hour for $8 \mathrm{~h}$ each night using night vision cameras. The videotapes were scored, and the duration of self-injurious oral contact was calculated as percentage of the total time sampled.

Tissue injury was also examined in each rat, each time it was injected (i.e. twice per day for 5 days). These examinations consisted of visual inspection of each rat's head, forepaws, ventrum (ventral thorax and abdomen), hindpaws and tail, and each examination was videotaped. An injury score (table 1) was assigned to describe the presence (or absence) and severity of all injuries. These examinations were also performed on the morning of the sixth day, but no injections were administered. Immediately after this final inspection each rat was terminated. The tissue injury was then independently rescored from the videotape recordings by a trained observer, who was blind to the experimental conditions. The interexperimenter reliability was $94 \%$, and in the $6 \%$ of cases where the experimenters' ratings differed, they never differed by more than 1 point on the rating scale.

Grooming, inactivity and locomotion were also scored from the videotaped time samples. Grooming was defined as oral contact that continuously moved from one body part to another (i.e. the contact was not sustained on any specific body part for longer than $2 \mathrm{~s}$ ). Inactivity was defined as a complete lack of movement 


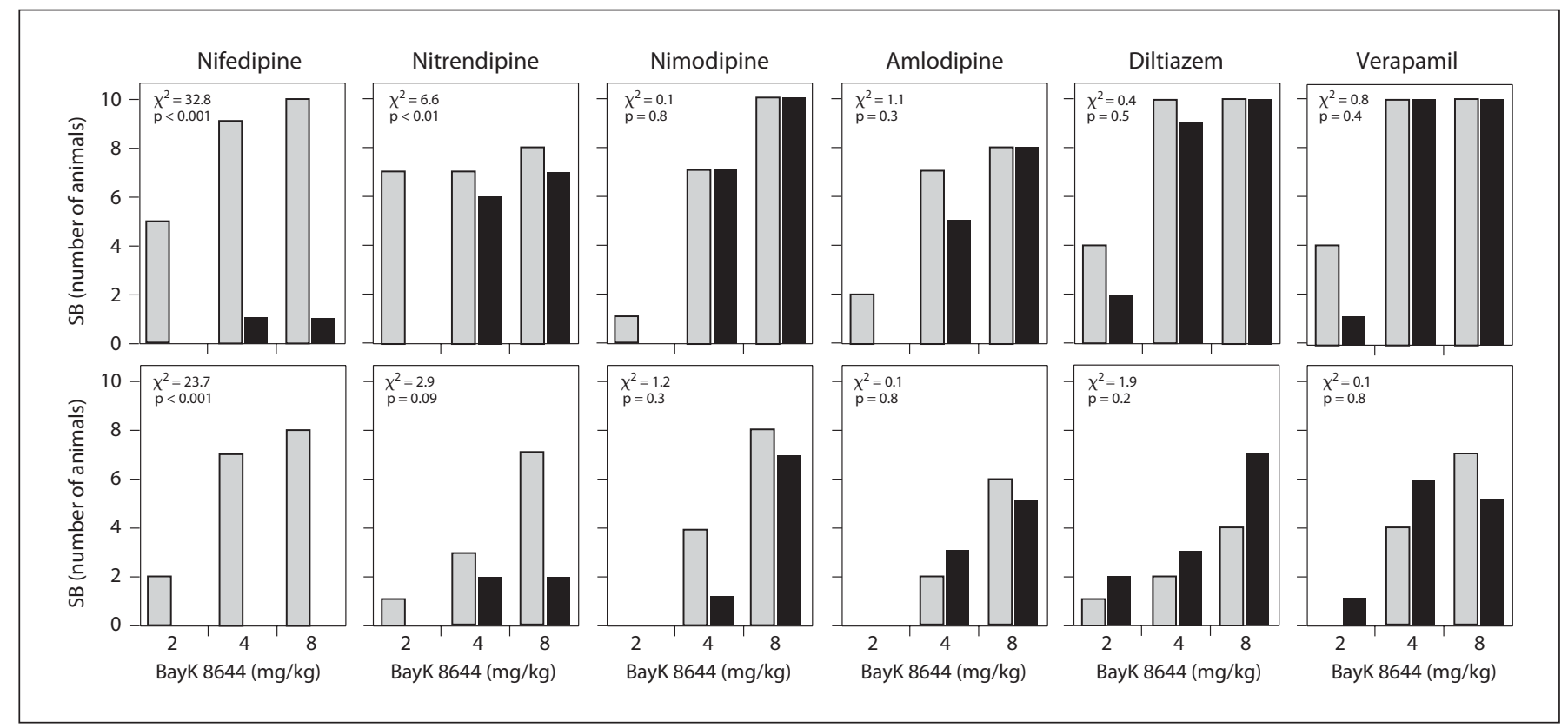

Fig. 1. Calcium channel antagonists suppress SB and SIB in response to \pm BayK 8644 . The top row of panels shows the frequencies of SB, while the bottom row shows SIB. The calcium channel antagonists $(20 \mathrm{mg} / \mathrm{kg}$ each) are noted above the panels. The results for these antagonists are shown as black bars, while the corresponding control group is shown in gray. Ten mice were tested under each drug and dose condition. The results of the $\chi^{2}$ statistical analysis comparing the influence of the antagonist with its corresponding control group are shown within each panel.

Table 1. Tissue injury rating scale

\begin{tabular}{ll}
\hline Score & Description \\
\hline 0 & No injury \\
1 Very mild injury & $\begin{array}{l}\text { Denuded skin, edema or erythema; } \\
\text { involves small area } \\
\text { Denuded skin, edema or erythema; } \\
\text { involves medium area or multiple small } \\
\text { areas } \\
\text { Denuded skin, edema or erythema; } \\
\text { involves large area or multiple medium } \\
\text { sites } \\
\text { Open lesion, requires immediate } \\
\text { euthanasia }\end{array}$ \\
\hline
\end{tabular}

except respiratory movements, and the duration of grooming and inactivity were each calculated as percentages of the total time sampled. Locomotion was counted by sectioning the cage into 3 equal parts (along the length of the cage) and counting the number of times the rat crossed into a different section without returning to the section that it had occupied immediately prior to that movement.
Some rats were euthanized before the end of the experiment because they had an injury score of 4 (open lesion). In these cases the missing data were replaced by repeating the final scores that were recorded through to the end of the experiment. This strategy was used to avoid the potential that the group means would underestimate the self-injurious oral contact and tissue injury scores when the severest self-injurers were removed from any group. Between-group differences in self-injurious oral contact, tissue injury scores, grooming, inactivity and locomotion were each evaluated using repeated measures ANOVA. All significant effects were further analyzed with LSD posttests.

\section{Results}

\section{\pm BayK 8644 Model}

Increasing doses of \pm BayK 8644 alone led to higher frequencies of both SB and SIB in the vehicle-treated controls as previously reported [Jinnah et al., 1999; Kasim et al., 2002, 2006; Kasim and Jinnah, 2002, 2003], with most mice exhibiting SB and SIB after the highest dose (fig. 1). Pretreatment with nifedipine resulted in a marked suppression of SB and complete elimination of SIB at all doses of BayK 8644 (fig. 1). 
Table 2. Methamphetamine model

\begin{tabular}{|c|c|c|c|}
\hline Treatment group & SB & SIB & Mortality \\
\hline \multicolumn{4}{|l|}{ Experiment 1} \\
\hline Methamphetamine alone & $10 / 12$ & $2 / 12$ & $1 / 12$ \\
\hline $\begin{array}{l}\text { Methamphetamine }+5 \mathrm{mg} / \mathrm{kg} \\
\text { nifedipine }\end{array}$ & $5 / 12$ & $0 / 12$ & $0 / 12$ \\
\hline \multicolumn{4}{|l|}{ Experiment 2} \\
\hline Methamphetamine alone & $11 / 12$ & $4 / 12$ & $1 / 12$ \\
\hline $\begin{array}{l}\text { Methamphetamine }+10 \mathrm{mg} / \mathrm{kg} \\
\text { nifedipine }\end{array}$ & $1 / 12$ & $0 / 12$ & $0 / 12$ \\
\hline \multicolumn{4}{|l|}{ Experiment 3} \\
\hline Methamphetamine alone & $8 / 12$ & $4 / 12$ & $0 / 12$ \\
\hline $\begin{array}{l}\text { Methamphetamine }+20 \mathrm{mg} / \mathrm{kg} \\
\text { nifedipine }\end{array}$ & $0 / 12$ & $0 / 12$ & $0 / 12$ \\
\hline
\end{tabular}

A $\chi^{2}$ analysis comparing animals treated with or without nifedipine revealed significant effects on both $\mathrm{SB}\left(\chi^{2}=29.4, \mathrm{p}<0.001\right)$ and SIB $\left(\chi^{2}=11.6, \mathrm{p}<0.001\right)$.

To determine if other L-type calcium channel antagonists might have similar effects, additional groups of drug-naïve mice were used to test 5 other calcium channel antagonists in the same manner. Pretreatment with nitrendipine also significantly suppressed SB in response to \pm BayK 8644 (fig. 1). Nitrendepine produced a trend for reduced SIB that was not statistically significant. No significant reduction of SB or SIB was apparent following pretreatments with nimodipine, amlodipine, diltiazem or verapamil. These results indicate that only some Ltype calcium channel antagonists can suppress SB and SIB.

\section{Methamphetamine Model}

Further studies of other animal models of SB and SIB focused on nifedipine, since it seemed to have the greatest impact on these behaviors in the \pm BayK 8644 model. Independent groups of drug-naïve Balb/c mice each received subcutaneous injection of $5 \mathrm{mg} / \mathrm{kg}$ of nifedipine or vehicle, immediately followed by $10 \mathrm{mg} / \mathrm{kg}$ of methamphetamine. The administration of $10 \mathrm{mg} / \mathrm{kg}$ of methamphetamine alone induced SB in a high proportion of mice, with a small proportion progressing to SIB (table 2). Pretreatment with $5 \mathrm{mg} / \mathrm{kg}$ of nifedipine suppressed SB and eliminated SIB in response to methamphetamine.

Additional groups of drug-naïve mice were used to evaluate the effects of higher nifedipine pretreatment doses (10 or $20 \mathrm{mg} / \mathrm{kg}$ ) on methamphetamine-induced $\mathrm{SB}$ and SIB. These higher doses of nifedipine resulted in

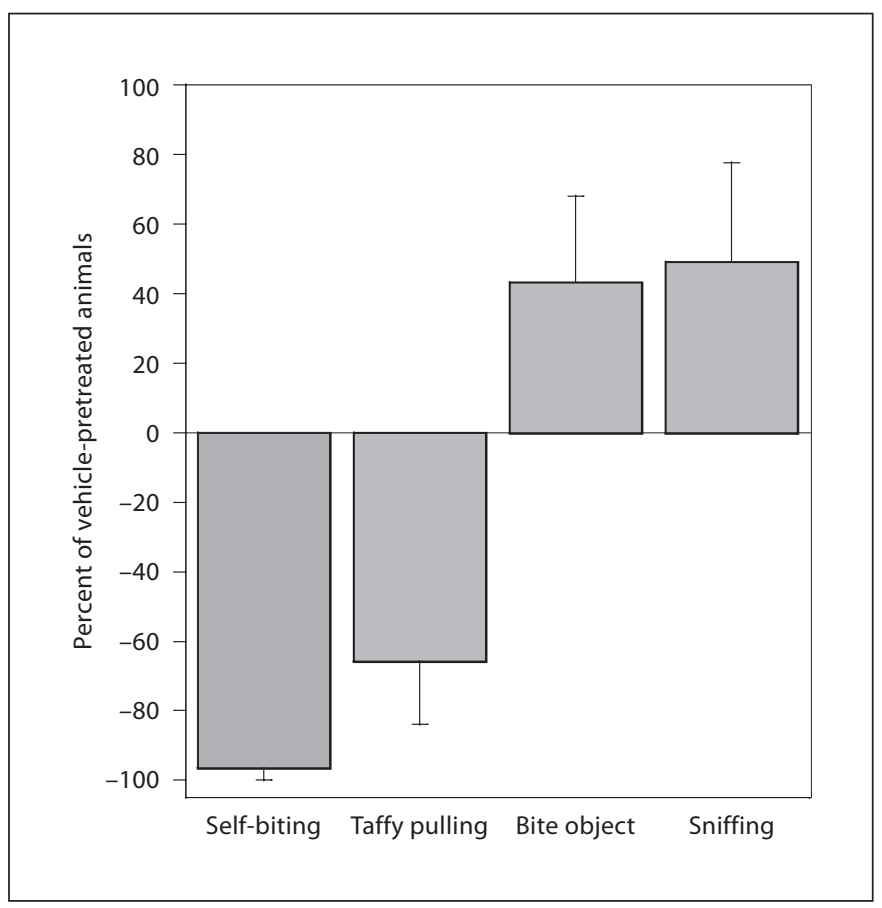

Fig. 2. Nifedipine alters the frequency of stereotypical behaviors after a single dose of methamphetamine. The results show the average percentage of the time the animals spent engaging in the behavior, expressed as a percentage of vehicle-treated controls $( \pm S E M)$. With $10 \mathrm{mg} / \mathrm{kg}$ of nifedipine, SB and taffy pulling were significantly decreased, while repetitive sniffing or licking/biting the cage walls were increased $(\mathrm{p}<0.01)$.

an even greater suppression of SB and again eliminated SIB, in response to methamphetamine (table 2).

Pretreatment with nifedipine also influenced other stereotypical behaviors (fig. 2). Taffy pulling, a repetitive hand-mouth behavior that often precedes SIB, was significantly reduced by nifedipine. Other stereotypical behaviors, such as sniffing or licking the cage, were increased. These results argue that nifedipine does not exert a nonspecific suppression of all behaviors (e.g. sedation) but rather modifies the profile of behaviors.

\section{OHDA Model}

The susceptibility of the lesioned rats to exhibit SB and SIB was first verified by administering vehicle intraperitoneally, followed by $10 \mathrm{mg} / \mathrm{kg}$ of apomorphine subcutaneously $10 \mathrm{~min}$ later. The vehicle pretreatment was repeated for each experiment involving 1 of 3 doses of nifedipine. Behavioral observations made over $90 \mathrm{~min}$ following apomorphine injection revealed that $84 \%$ of all vehicle-pretreated rats lesioned as neonates engaged in 


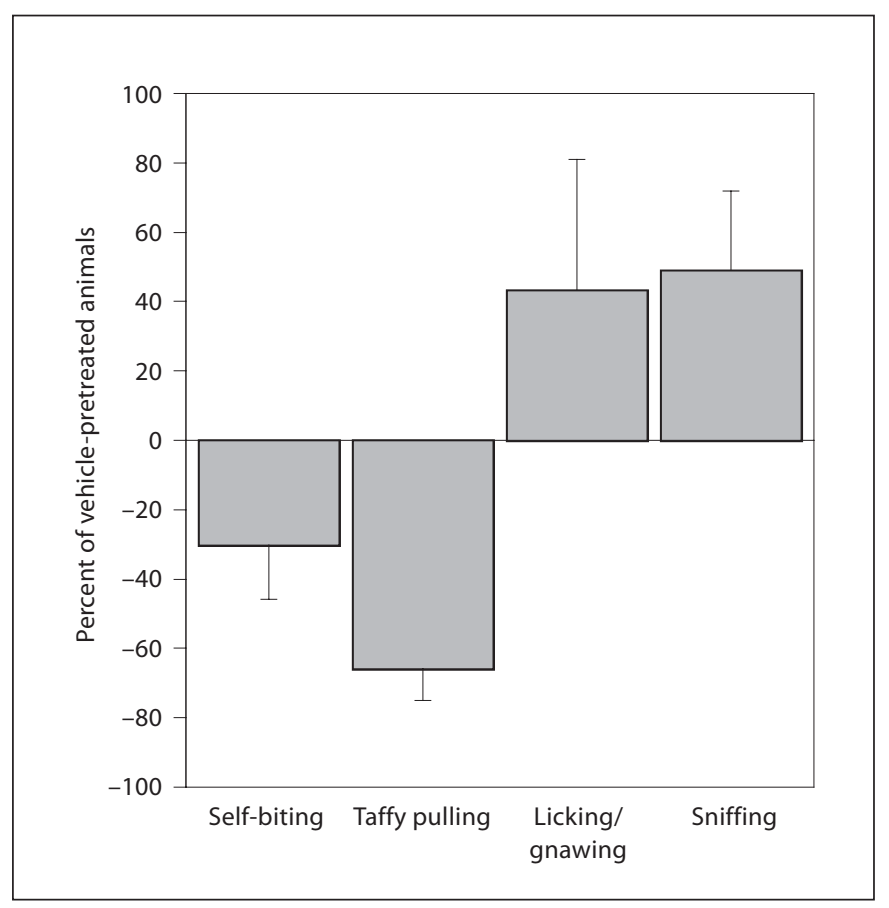

Fig. 3. Nifedipine $(10 \mathrm{mg} / \mathrm{kg})$ alters the frequency of stereotypical behaviors after apomorphine treatment of rats with neonatal $6 \mathrm{OHDA}$ lesions. The fraction of time that nifedipine-pretreated rats were observed engaging in behaviors is expressed as the average percent of vehicle-treated rats ( \pm SEM). Compared to vehicle, pretreatment with $10 \mathrm{mg} / \mathrm{kg}$ of nifedipine significantly reduced the percentage of time the rats spent taffy pulling $(p<0.001)$ and significantly increased the time they spent sniffing $(\mathrm{p}<0.01)$. The trends towards increased gnawing/licking the cage and reduced SB were not significant $(\mathrm{p}>0.10)$.

SB (38 of 45), while 67\% (30 of 45) exhibited SIB. These findings are in close accordance with previous results using L-dopa rather than apomorphine [Breese et al., 1984].

One week after the vehicle-apomorphine pretreatments, the rats were injected with 5,10 or $20 \mathrm{mg} / \mathrm{kg}$ of nifedipine, followed by $10 \mathrm{mg} / \mathrm{kg}$ of apomorphine $10 \mathrm{~min}$ later. Nifedipine attenuated both SB and SIB (table 3). Among the animals that bit themselves during the 90min observation period, there was a delayed onset of SB in both the $10-$ and $20-\mathrm{mg} / \mathrm{kg}$ nifedipine groups (not shown).

Nifedipine also modified the expression of other stereotypical behaviors in this model. Taffy pulling was decreased, whereas sniffing or gnawing/licking the cage wall were increased. These observations suggest a change in the topography of behaviors rather than a global suppression of all behaviors (fig. 3).
Table 3. Neonatal 6OHDA model

\begin{tabular}{|c|c|c|}
\hline Treatment group & SB & SIB \\
\hline \multicolumn{3}{|l|}{ Experiment 1} \\
\hline Vehicle & $10 / 10$ & $6 / 10$ \\
\hline Nifedipine (5 mg/kg) & $9 / 10$ & $5 / 10$ \\
\hline \multicolumn{3}{|l|}{ Experiment 2} \\
\hline Vehicle & $19 / 19$ & $15 / 19$ \\
\hline Nifedipine (10 mg/kg) & $16 / 19$ & $10 / 19$ \\
\hline \multicolumn{3}{|l|}{ Experiment 3} \\
\hline Vehicle & $13 / 16$ & $9 / 16$ \\
\hline Nifedipine (20 mg/kg) & $8 / 16$ & $4 / 16$ \\
\hline \multicolumn{3}{|c|}{$\begin{array}{l}\text { A } \chi^{2} \text { analysis comparing animals treat- } \\
\text { ed with or without nifedipine revealed a } \\
\text { significant effect on } \mathrm{SB}\left(\chi^{2}=5.4, \mathrm{p}<0.02\right) \text {, } \\
\text { but the effect on } \mathrm{SIB} \text { was not significant } \\
\left(\chi^{2}=1.7, \mathrm{p}=0.2\right) .\end{array}$} \\
\hline
\end{tabular}

\section{Pemoline Model}

The daily treatment of the rats with pemoline led to a progressive increase in the severity of SB and SIB expressed as the duration of self-injurious oral contact or the severity of tissue injury (fig. 4) as previously described [Kies and Devine, 2004]. The treatment with nifedipine (3, 10 or $30 \mathrm{mg} / \mathrm{kg}$ b.i.d. for 5 days) significantly lessened the duration of pemoline-induced self-injurious oral contact and the severity of tissue injury across the days of the experiment.

Nifedipine did not significantly affect any of the other measured behaviors, including grooming, time inactive or the amount of locomotion (fig. 5).

\section{Discussion}

SIB in humans has many different clinical manifestations. For specific and well-defined causes of the behavior, the manifestations are relatively stereotyped. Examples include stereotypical skin picking in Prader-Willi syndrome, recurrent biting in Lesch-Nyhan disease and head banging in autism [Symons et al., 1999; Schroeder et al., 2001; Robey et al., 2003; Schretlen et al., 2005]. The more stereotyped patterns of SIB in the well-defined disorders suggest that the differing clinical manifestations are in part due to differing etiologies. The heterogeneity of the underlying causes makes finding universally useful treatments challenging because the treatment must 
simultaneously address multiple different biological mechanisms. In this situation the identification of shared neural pathways or common biochemical mechanisms holds great promise for identifying potential new therapies.

Animal models that express SIB can be useful for investigating underlying biological mechanisms and for preliminary screening of potential new therapies. Similar
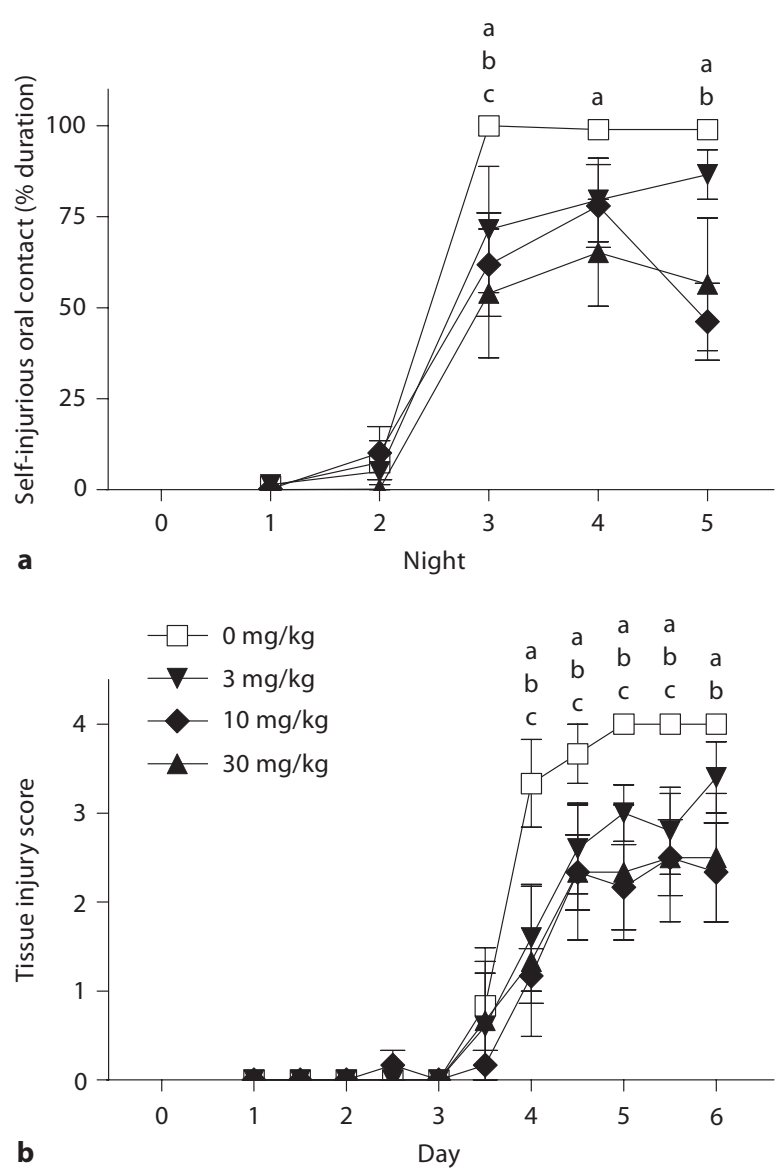

Fig. 4. Nifedipine reduces SB and SIB in pemoline-treated rats. a Average duration of self-injurious oral contact, measured as percentage of the time during which sustained oral contact occurred during the videotaped overnight time samples. b Tissue injury scores, as measured according to table 1 . All values are expressed as group means \pm SEM. Significant differences between rats treated with vehicle or nifedipine (LSD) are depicted as follows: ${ }^{\mathrm{a}} \mathrm{p}<0.05$ for comparisons between nifedipine at $30 \mathrm{mg} / \mathrm{kg}$ and vehicle, ${ }^{\mathrm{b}} \mathrm{p}<0.05$ for comparisons between nifedipine at $10 \mathrm{mg} / \mathrm{kg}$ and vehicle, and ${ }^{\mathrm{c}} \mathrm{p}<0.05$ for comparisons between nifedipine at $3 \mathrm{mg} / \mathrm{kg}$ and vehicle.
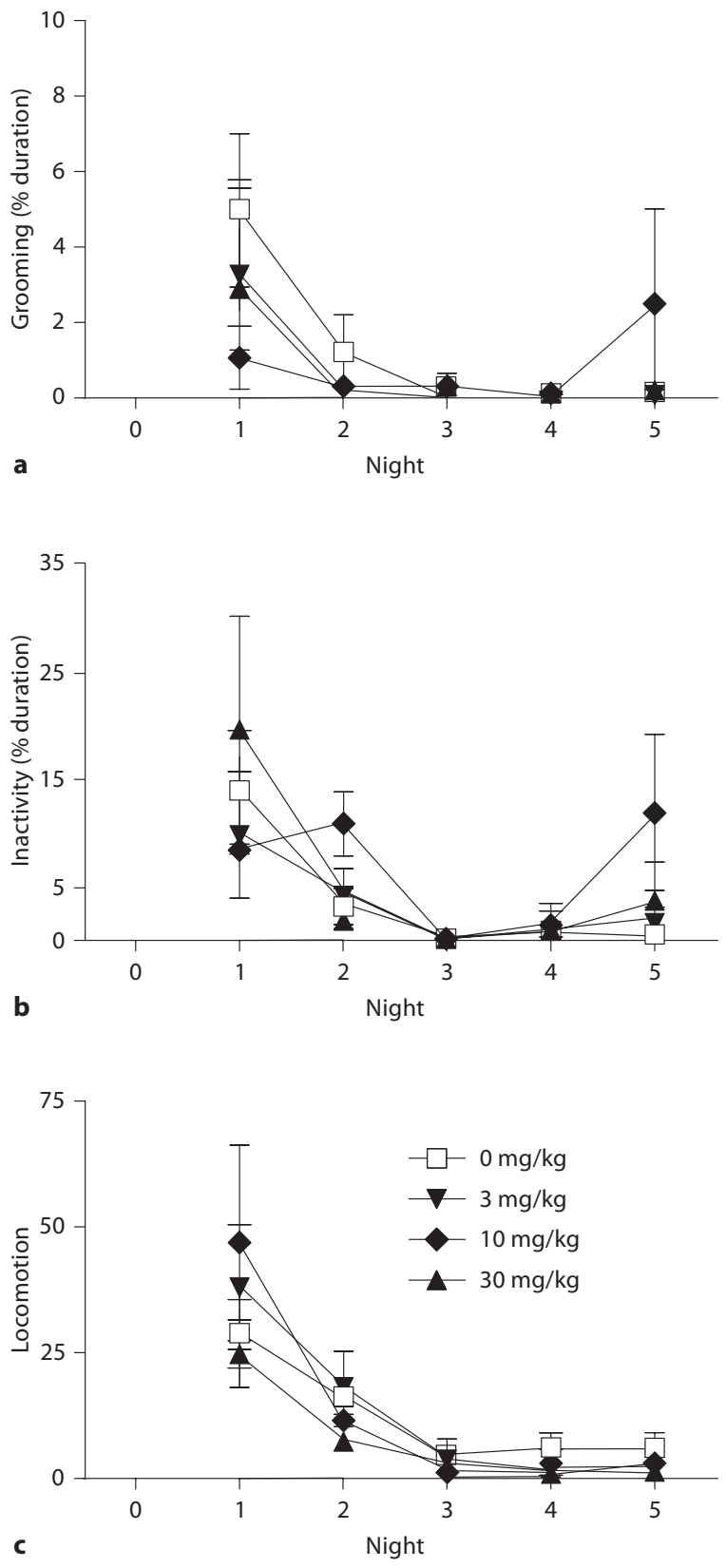

Fig. 5. The effect of nifedipine on other pemoline-induced behaviors in rats. The time spent grooming $\left(\mathbf{a} ; \mathrm{F}_{4,72}=4.6, \mathrm{p}<0.01\right)$ or inactive $\left(\mathbf{b} ; \mathrm{F}_{4,72}=6.7, \mathrm{p}<0.01\right)$ and the amount of locomotion (c; $\mathrm{F}_{4,72}=23.9, \mathrm{p}<0.01$ ) recorded on videotapes overnight all decreased significantly across the days of the experiment, but no significant between-group effects or group by time interaction effects were found. 
to humans, SIB in animals has many different manifestations. For example, biting is the most common form of SIB, but the topography differs among the models. The forepaws and digits are the most frequent targets in many of the models, whereas the ventrum or tail are frequent targets in the caffeine model [Mueller et al., 1982; Kies and Devine, 2004]. The temporal profile of SIB also differs among the models. It evolves slowly over days with chronic treatment in the pemoline and caffeine models [Mueller et al., 1982; Kies and Devine, 2004], requires repeated daily challenges in the neonatal 6OHDA model [Breese et al., 2004] and occurs within minutes in the \pm BayK model [Jinnah et al., 1999; Kasim and Jinnah, 2003]. The comorbid behaviors also differ. The stereotypies are universal in the psychostimulant and neonatal 6OHDA models, less prominent in the caffeine model and absent in the \pm BayK model [Kasim and Jinnah, 2002; Kies and Devine, 2004].

The biological mechanisms underlying SIB also differ among the animal models. The psychostimulant and neonatal 6OHDA models involve dopaminergic mechanisms, whereas the BayK 8644 model involves calcium channels. Recent studies have shown a link between the calcium channels influenced by BayK 8644 and dopamine receptors, though the ability of BayK 8644 to provoke SIB does not require presynaptic dopamine or postsynaptic dopamine receptor integrity [Kasim and Jinnah, 2003; Kasim et al., 2006]. The mechanisms underlying the caffeine model remain uncertain because the high doses needed obscure pharmacological specificity [Jinnah et al., 1990].

The ability of nifedipine to suppress SIB in multiple animal models is noteworthy, considering the differing manifestations and underlying causes. Nifedipine does not suppress all behaviors in these models and in fact increases certain classes of stereotypical behaviors, such as repetitive sniffing, in the methamphetamine and 6OHDA models. These observations suggest that nifedipine does not suppress SIB by nonspecific mechanisms such as sedation. The mechanisms by which nifedipine suppresses SIB will require further investigation. Nifedipine is best known for its ability to block L-type voltage-regulated calcium channels, which are widely expressed in the brain and body [Jinnah et al., 2004]. It seems feasible that the channels linked with striatal dopamine pathways could play a role in a shared pathway in the expression of SIB [Kasim et al., 2006].

If L-type calcium channels play a role in the expression of SIB, other antagonists of these channels should have the same beneficial effects as nifedipine. This prediction was evaluated in the \pm BayK 8644 model for SIB by evaluating 5 other drugs. Nitrendipine was indeed effective in suppressing SB with a trend for reducing SIB, but 4 other calcium channel antagonists were not (nimodipine, amlodipine, diltiazem and verapamil). The reasons for the lack of uniform efficacy are not clear, though several possibilities could be considered. Some drugs (verapamil) do not cross the blood-brain barrier, limiting the access to relevant neural pathways. Other drugs (amlodipine) exhibit an idiosyncratic state-dependent blockade of the calcium channel, potentially limiting the efficacy under certain circumstances. Finally the L-type calcium channels comprise multiple distinct isoforms with different tissue distributions and different regional localizations within the brain [Hetzenauer et al., 2006]. The available drugs may differentially influence these channel subtypes. Further studies may be useful for clarifying the reasons for differing efficacy among the calcium channel antagonists in the BayK 8644 model, for determining if similar patterns of efficacy exist in the other models of SIB and for identifying related drugs with an even greater efficacy than nifedipine.

In addition to the apparent differences in efficacy among the L-type calcium channel antagonists in the BayK 8644 model, there may also be differences in the efficacy of nifedipine across the different models. Though strict quantitative comparisons across these models are not possible because the data were collected by different centers using different methods, some trends are apparent. Nifedipine eliminated SIB in the BayK 8644 and methamphetamine models, reduced tissue injury scores by $30-50 \%$ in the pemoline model and caused a nonsignificant trend for reduced SIB in the 6OHDA model. Some of these apparent differences in efficacy may result from purely pharmacokinetic issues. The short half-life of nifedipine limits its effective duration to $<90 \mathrm{~min}$, rendering it most useful in the acute models (BayK 8644 and methamphetamine). It would be predicted to be less effective in the pemoline model, due to the very long halflife of pemoline [Kies and Devine, 2004]. Further studies of long-acting preparations of nifedipine or other longacting L-type calcium channel antagonists might help resolve this issue. Other differences in the apparent efficacy of nifedipine across the models may be model specific. For example, full development of SIB in the 6OHDA model requires repeated dosing of apomorphine, a phenomenon known as priming [Criswell et al., 1989]. The ability of nifedipine to suppress SIB in this model may therefore require further studies to distinguish an effect of the drug on the behavior versus the priming process. 
Despite these differences among the models, it is notable that nifedipine was at least partly effective in reducing SB or SIB in all of them.

In humans nifedipine has not yet received much attention for SIB, but it has been used for decades in the treatment of other disorders such as hypertension. It has proven very safe, with no serious side effects even during chronic therapy. It has been used in both children and adults. It has minimal central nervous system side effects such as sedation or agitation. These relatively benign properties contrast with those of the neuroleptics, which have also been proposed for the treatment of populations with SIB [Luchins, 1991; McDonough et al., 2000; Schroeder et al., 2001; Breese et al., 2004]. Unfortunately a widespread adoption of neuroleptics for SIB is not likely because of variable efficacy and several unwanted side effects. The neuroleptics are often sedating at doses used to suppress
SIB, making it difficult to separate a specific influence on SIB from sedation. The problem of sedation is particularly challenging for populations with comorbid mental retardation. Neuroleptics also carry a significant risk for shortterm side effects such as drug-induced parkinsonism, akathisia, acute dystonic reactions and the neuroleptic malignant syndrome. Most troublesome is the risk of neuroleptic-induced tardive dyskinesia, which can be permanent and disabling. In view of the efficacy of nifedipine in multiple animal models and its safety track record in humans, it seems an attractive candidate for a clinical trial.

\section{Acknowledgments}

This work was supported by NIH PHS grant HD39795 and a grant from the National Alliance for Autism Research.

\section{References}

Anderson LT, Ernst M (1994): Self-injury in Lesch-Nyhan disease. J Autism Dev Disord 24:67-81.

- Breese GR, Baumeister AA, McCown TJ, Emerick SG, Frye GD, Crotty K, Mueller RA (1984): Behavioral differences between neonatal and adult 6-hydroxydopamine-treated rats to dopamine agonists: relevance to neurological symptoms in clinical syndromes with reduced brain dopamine. J Pharmacol Exp Ther 231:343-354.

- Breese GR, Knapp DJ, Criswell HE, Moy SS, Papadeas ST, Blake BL (2004): The neonate 6hydroxydopamine lesioned rat: a model for clinical neuroscience and neurobiological principles. Brain Res Rev 48:57-73.

Criswell H, Mueller RA, Breese GR (1989): Priming of $\mathrm{D}_{1}$ dopamine receptor responses: longlasting behavioral supersensitivity to a $D_{1}$ dopamine agonist following repeated administration to neonatal 6-OHDA-lesioned rats. J Neurosci 9:125-133.

-Cromwell HC, Levine MS, King BS (1999): Cortical damage enhances pemoline-induced self-injurious behavior in prepubertal rats. Pharmacol Biochem Behav 62:223-227.

-Dickson PR, Lang CG, Hinton SC, Kelley AE (1994): Oral stereotypy induced by amphetamine microinjection into striatum: an anatomical mapping study. Neuroscience 61: 81-91.

- Halladay AK, Kusnecov A, Hichna L, Kita T, Hara C, Wagner CC (2003): Relationship between methamphetamine-induced dopamine release, hyperthermia, self-injurious behavior and long-term dopamine depletion in $\mathrm{BALB} / \mathrm{c}$ and $\mathrm{C} 57 \mathrm{BL} / 6$ mice. Pharmacol Toxicol 93:33-41.

Nifedipine and Self-Injurious Behavior
Hetzenauer A, Sinnegger-Brauns MJ, Striessnig J, Singewald N (2006): Brain activation pattern induced by stimulation of L-type $\mathrm{Ca}^{2+}$ channels: contribution of $C a_{V} 1.3$ and $C a_{V} 1.2$ isoforms. Neuroscience 139:1005-1015.

Huberman HS, Eison MS, Bryan KS, Ellison G (1977): A slow-release silicone pellet for chronic amphetamine administration. Eur J Pharmacol 45:237-242.

Jinnah HA, Egami K, Rao K, Shin MY, Kasim S, Hess EJ (2004): Expression of c-fos in the brain after activation of L-type calcium channels. Dev Neurosci 25:403-411.

Jinnah HA, Gage FH, Friedmann T (1990): Animal models of Lesch-Nyhan syndrome. Brain Res Bull 25:467-475.

Jinnah HA, Yitta S, Drew T, Kim BS, Visser JE, Rothstein JD (1999): Calcium channel activation and self-biting in mice. Proc Natl Acad Sci USA 96:15228-15232.

Kasim S, Blake BL, Fan X, Chartoff EH, Egami $\mathrm{K}$, Breese GR, Hess EJ, Jinnah HA: The role of dopamine receptors in the neurobehavioral syndrome provoked by activation of Ltype calcium channels in mice. Dev Neurosci, in press.

Kasim S, Egami K, Jinnah HA (2002): Self-biting induced by activation of L-type calcium channels in mice: serotonergic influences. Dev Neurosci 24:322-327.

Kasim S, Jinnah HA (2002): Thresholds for selfinjurious behavior in a genetic mouse model of Lesch-Nyhan disease. Pharmacol Biochem Behav 73:583-592.

Kasim S, Jinnah HA (2003): Self-biting induced by activation of L-type calcium channels in mice: dopaminergic influences. Dev Neurosci $25: 20-25$.
Kelley AE, Gauthier AM, Lang CG (1989): Amphetamine microinjections into distinct striatal subregions cause dissociable effects on motor and ingestive behavior. Behav Brain Res 35:24-39.

Kelley AE, Lang CG, Gauthier AM (1988): Induction of oral stereotypy following amphetamine microinjection into a discrete subregion of the striatum. Psychopharmacology 95:556-559.

Kies S, Devine DP (2004): Self-injurious behavior: a comparison of caffeine and pemoline in rats. Pharmacol Biochem Behav 79:587598.

King BH, Au D, Poland RE (1995): Pretreatment with MK-801 inhibits pemoline-induced self-biting behavior in prepubertal rats. Dev Neurosci 17:47-52.

-King BH, Cromwell HC, Lee HT, Behrstock SP, Schmanke T, Maidment NT (1998): Dopaminergic and glutamatergic interactions in the expression of self-injurious behavior. Dev Neurosci 20:180-187.

- Kita T, Matsunari Y, Saraya T, Shimada K, O’Hara K, Kubo K, Wagner GC, Nakashima T (2000): Methamphetamine-induced striatal dopamine release, behavior changes and neurotoxicity in $\mathrm{BALB} / \mathrm{c}$ mice. Int $\mathrm{J}$ Dev Neurosci 18:521-560.

-Kratofil PH, Baberg HT, Dimsdale JE (1996): Self-mutilation and severe self-injurious behavior associated with amphetamine psychosis. Gen Hosp Psychiatry 18:117-120.

Luchins DJ (1991): A review of pharmacological agents for self-injurious behavior. Prog Neuropsychopharmacol Biol Psychiatry 14: S169-S179.
-

Dev Neurosci 2007;29:241-250 
McDonough M, Hillery J, Kennedy N (2000): Olanzepine for chronic, stereotypic self-injurious behaviour: a pilot study in seven adults with intellectual disability. J Intellect Disabil Res 44:677-684.

-Mueller K, Hollingsworth E, Pettit H (1986): Repeated pemoline produces self-injurious behavior in adult and weanling rats. Pharmacol Biochem Behav 25:933-938.

- Mueller K, Nyhan WL (1982): Pharmacologic control of pemoline-induced self-injurious behavior in rats. Pharmacol Biochem Behav 16:957-963.

Mueller K, Saboda S, Palmour R, Nyhan WL (1982): Self-injurious behavior produced in rats by daily caffeine and continuous amphetamine. Pharmacol Biochem Behav 17: 613-617.
Papadeas ST, Blake BL, Knapp DJ, Breese GR (2004): Sustained extracellular signal-regulated kinase $1 / 2$ phosphorylation in neonate 6-hydroxydopamine-lesioned rats after repeated $\mathrm{D}_{1}$ dopamine receptor agonist administration: implications for NMDA receptor involvement. J Neurosci 26:5863-5876.

Robey KL, Reck JF, Giacomini KD, Barabas G Eddey GE (2003): Modes and patterns of selfmutilation in persons with Lesch-Nyhan disease. Dev Med Child Neurol 45:167-171.

Schretlen DS, Ward J, Meyer SM, Yun J, Puig JG, Nyhan WL, Jinnah HA, Harris JC (2005): Behavioral aspects of Lesch-Nyhan disease and its variants. Dev Med Child Neurol 47: 673-677.

Schroeder SR, Oster-Granite ML, Berkson G, Bodfish JW, Breese GR, Cataldo MF, Cook EH, Crnic LS, Fisher W, Harris JC, Horner RH, Iwata B, Jinnah HA, King BH, Lauder JM, Lewis MH, Newell K, Nyhan WN, Rojahan J, Sackett GP, Sandman C, Symons F, Tessel RE, Thompson T, Wong DF (2001): Self-injurious behavior: gene, brain, behavior relationships. Ment Retard Dev Disabil Res Rev 7:3-12.
Sokol MS, Campbell M, Goldstein M, Kriechman AM (1991): Attention deficit disorder with hyperactivity and the dopamine hypothesis: case presentations with theoretical background. J Am Acad Child Adolesc Psychiatry 26:428-433.

Symons FJ, Butler MG, Sander MD, Feurer ID, Thompson T (1999): Self-injurious behavior and Prader-Willi syndrome: behavioral forms and body locations. Am J Ment Retard 104:260-269.

Visser JE, Baer PR, Jinnah HA (2000): Lesch-Nyhan syndrome and the basal ganglia. Brain Res Brain Res Rev 32:449-475. 